\title{
PRODUÇÃO DO JOGO PERFIL PARA CARACTERIZAÇÃO DE PERSONAGENS
}

\section{Barbara Delgado Azevedo ${ }^{1}$ \\ Mariana Souza Veiga ${ }^{2}$}

Apresentação

Neste relato, apresentaremos o trabalho desenvolvido com uma turma de sétimo ano do Colégio de Aplicação João XXIII, como parte da disciplina de Estágio Supervisionado de Língua Portuguesa, do curso de Letras, da Universidade Federal de Juiz de Fora.

Trabalhamos sob a orientação da professora regente da turma, no caso, uma turma de $7^{\circ}$ ano do Ensino Fundamental II, com o uso de gênero textuais, por meio de uma sequência didática, para desenvolver as capacidades de linguagem dos alunos, mais especificamente as que tangem a leitura de textos literários. Dessa forma, as aulas planejadas foram uma continuidade do trabalho que já vinha sendo feito pela professora, com base em um livro de aventura fantástica: Percy Jackson.

O objetivo dessa sequência didática, com tema proposto pela professora, era o de se trabalhar as características dos personagens mais relevantes desse volume, para que, assim, eles conseguissem dar continuidade e ler o segundo livro. Para isso, recorremos ao modelo de sequência didática proposto por Dolz e Scheneuwly (2010), além de autores como Bakhtin e Vigotsky, que acreditam numa perspectiva interacionista.

\section{Caracterização da escola}

O Colégio de Aplicação XXIII está localizado no bairro Santa Helena, região central de Juiz de Fora, e teve sua fundação em 1965. Por ser uma Unidade Acadêmica da UFJF, recebe muitos bolsistas e estagiários da universidade, contribuindo para a formação não só destes, mas, também, dos alunos.

\footnotetext{
${ }^{1}$ Mestranda em Linguística pela Universidade Federal de Juiz de Fora (UFJF) - barbaradelgadoa@gmail.com

${ }^{2}$ Especializanda em Linguagem, Tecnologia e Ensino pela Universidade Federal de Minas Gerais (UFMG) veigamariana1995@gmail.com
}

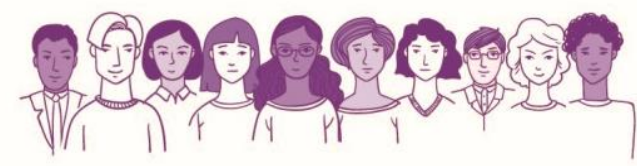


A instituição tem cerca de 89 professores de dedicação exclusiva que atendem, aproximadamente, 1320 alunos, distribuídos em 28 turmas de Ensino Fundamental, 09 turmas de Ensino Médio e 09 turmas do EJA.

O colégio tem um espaço físico excelente, conta com quadra poliesportiva, salas de vídeo, biblioteca, infocentro e oferece lanche gratuitamente aos alunos no recreio. Além disso, os alunos podem se matricular em aulas extracurriculares de dança, circo, esportes etc.

A turma acompanhada durante o Estágio Supervisionado de Língua Portuguesa I era composta por trinta e dois alunos que, em sua maioria, assistiam às aulas apenas no turno da manhã (de sete e dez às onze e quarenta). Todavia, alguns deles participavam do "Laboratório de Aprendizagem" (LA) à tarde. O LA é um espaço para aulas de reforço para alunos que apresentem dificuldade na disciplina. Toda disciplina do colégio oferece LA, que, no Ensino Fundamental II, funciona no sexto tempo (das 11:40 às 12:30) de segunda à sexta e no período da tarde para as disciplinas que não se encaixam na grade da manhã.

Os discentes, que tinham entre 11 e 12 anos no momento desta intervenção, faziam parte de uma das três turmas de sétimo ano do ensino fundamental da escola. A turma era bastante participativa e divertida e os alunos mantiveram um bom relacionamento com as estagiárias ao longo de todo o processo interventivo.

\section{Fundamentação teórica}

Os Parâmetros Curriculares Nacionais (PCN) orientam o ensino que valoriza a interação e a cooperação. Dessa forma, estabelecem que sejam proporcionadas aos alunos situações em que esses possam aprender a ler, escrever, ouvir e falar de forma mais apropriada a determinados contextos, ou seja, que sejam criadas situações em que possam agir socialmente.

Segundo Vygotsky, o sujeito age e interage na realidade a partir de relações intra e interpessoais, sendo na troca com outros sujeitos e consigo próprio que cria e internaliza seus conhecimentos, papéis e funções sociais. Assim, é por meio da interação que o indivíduo pode internalizar as relações que observa e os conhecimentos que adquire. Nessa visão, o desenvolvimento vai do externo para o interno.

Mikhail Bakhtin (1988) afirma que a interação socioverbal é a verdadeira natureza da linguagem, daí a concepção interacionista da língua como instrumento para o agir social, que carrega

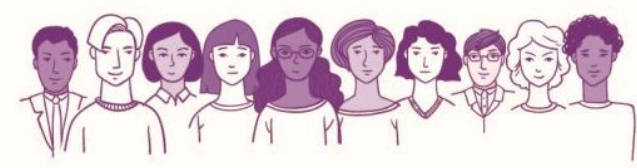


marcas históricas e sociais. Isto posto, acreditamos que a escola deve considerar as várias formas de agir por meio da linguagem, levando em conta as variedades de seus usos.

Ainda segundo Bakhtin (1985-1975), cada área de utilização da língua gera tipos relativamente estáveis de enunciados, agrupados por seus conteúdos temáticos, estilo e construção composicional, chamados de gêneros do discurso. Marcuschi (2003) afirma que é por meio de tais gêneros cotidianos que compreendemos e desenvolvemos nossos papéis de agentes na sociedade. Assim, podemos considerar que a escola deve re(construir) as relações que o aluno faz entre a língua e seu uso real em sociedade, levando em conta seu conhecimento prévio e buscando ampliar seu acervo de gêneros.

Acreditamos no trabalho com os gêneros textuais em sala de aula como instrumento de aprendizagem e não como objeto de ensino. Para isso, devem ser trabalhados mais que aspectos puramente estruturais do texto, ensinados tradicionalmente de forma sistemática e descontextualizada, mas aspectos sociais de uso, função, distribuição e a compreensão de suas estruturas linguísticas essenciais.

A visão do gênero como instrumento nos permite o uso dos mais diferenciados enunciados em sala de aula. Uma vez que a função ultrapassa a memorização de características primárias, nada impede que o estudo do texto nas escolas seja similar àquelas praticadas "além dos muros da escola" (DOLZ; GAGNON E DECÂNDIO, 2010, p. 13), o que justifica a escolha de um gênero do domínio do lazer.

A motivação pela escolha do gênero para o trabalho se deu por diversos motivos, entre eles os jogos como ação social, a orientação dos PCNs, que sugerem o uso de jogos, a visão de Miranda (2002) de jogos como dispositivos facilitadores para a compreensão de conteúdos, além de promoverem um estímulo a participação dos alunos e a personalidade da turma, que se apresentou muito participativa e engajada.

Além disso, os jogos são práticas culturais presentes no cotidiano das sociedades desde a Antiguidade, em todas as épocas, em todos os povos. Segundo o Manual didático Jogos de alfabetização,

\footnotetext{
o jogo, além de constituir-se como veículo de expressão e socialização das práticas culturais da humanidade e veículo de inserção no mundo, é também uma atividade lúdica em que crianças e/ou adultos se engajam num mundo imaginário, regido por regras próprias, que, geralmente são construídas a partir das próprias regras sociais de convivência. (CEEL/UFPE, 2013 p.11)
}

Segundo Miranda (2002), a atividade lúdica permite ao aluno transformar em concreto os conhecimentos adquiridos. Assim, o uso de jogos em sala de aula não se limita ao lúdico, sendo

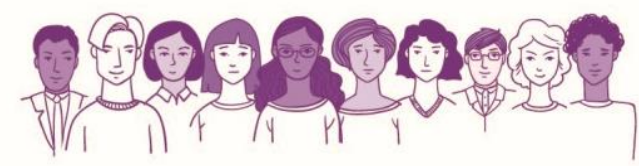


instrumento para a aprendizagem. No presente relato, buscamos apresentar como o jogo "Perfil" pode proporcionar a apropriação das características de alguns personagens de um determinado texto por parte dos alunos.

Desenvolvemos nossa atividade em forma da sequência didática (SD) proposta por Dolz e Scheneuwly (2010), na qual as atividades escolares giram em torno de um gênero textual oral ou escrito, com objetivo de auxiliar ao aluno dominar um gênero, em suas características sociais e discursivas, de forma a reconhecer, produzir e adequar-se aos seus contextos de uso. A sequência didática se dá em cinco etapas: situação de produção, a produção inicial, módulos de trabalho, produção final e distribuição:

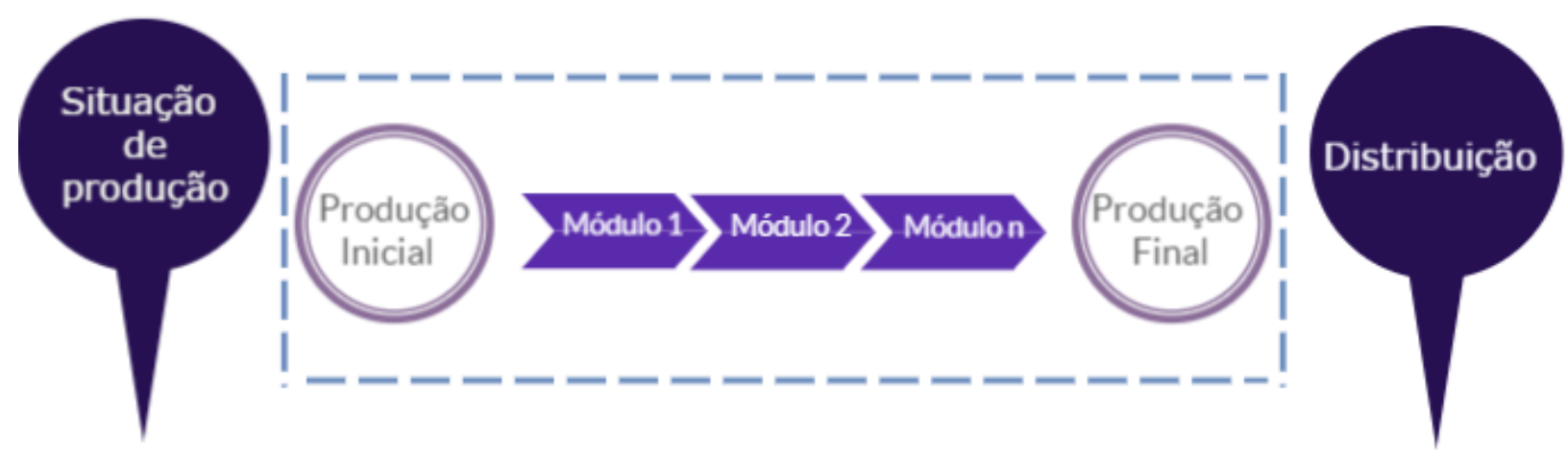

Figura 1. Sequência didática a partir de Dolz e Scheneuwly.

O jogo "Perfil" é um gênero textual de dedução. O jogo original é um produto vendido no mercado pela empresa Grow, no qual o objetivo é descobrir, através de dicas, qual é o perfil secreto de cada carta, podendo ser lugar, pessoa, ano ou coisa. Para esse trabalho, o jogo foi adaptado e só apresentava lugar ou pessoa, além de ter o número de dicas reduzido. $O$ jogo envolveu a participação de todos os alunos, que produziram as cartas e jogaram, de um moderador, que lê as fichas, de um tabuleiro e de pinos.

Dessa maneira, pudemos trabalhar a caracterização dos personagens do texto trabalhado em sala, uma vez que era necessária a apropriação de tais características para a produção e a adivinhação das fichas, o que demandou um trabalho mais cuidadoso durante a leitura dos textos. $O$ trabalho será descrito na próxima seção.

Descrição da experiência

A observação feita no período em que estivemos assistindo às aulas da turma e a nossa bagagem enquanto estudantes de Letras foram muito importantes para que fizéssemos as escolhas

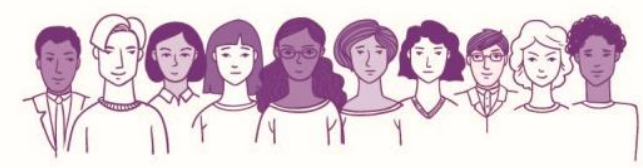


que julgamos apropriadas para aquela classe especificamente, ou seja, respeitando suas demandas e seus conhecimentos prévios. Além disso, a orientação da professora foi essencial tanto no período de preparação das aulas quanto na aplicação.

Durante o planejamento, fizemos a leitura dos dois primeiros livros da saga Percy Jackson e os Olimpianos: Percy Jackson e o Mar de Monstros (volume 2), para compreender sobre quais personagens seriam necessários o conhecimento prévio, e Percy Jackson e o Ladrão de Raios (volume 1) para selecionar os capítulos que melhor descrevessem tais personagens.

As atividades da sequência didática duraram pouco mais de 8 aulas, que serão descritas abaixo. O objetivo foi apresentarmos os personagens principais do livro Percy Jackson e o Ladrão de Raios, de Rick Riordan, uma vez que a professora iria trabalhar em sala o volume 2 da saga, Percy Jackson e o Mar de Monstros, e conhecer tais personagens seria essencial aos alunos.

Procuramos manter uma certa proximidade com a metodologia da professora, uma vez que o trabalho seria continuado depois por ela e para que houvesse uma harmonia nas aulas de uma forma geral. Desse modo, mantivemos, por exemplo, a leitura dos capítulos pouco adaptada e feita em voz alta pelos alunos, assim como já tinha sido feito durante o período observado.

A sequência didática se deu da seguinte forma: como situação de produção, tivemos a aula expositiva, a leitura dos textos, a apresentação do jogo e das fichas; a produção inicial foi a elaboração das fichas a serem preenchidas; os módulos foram restritos em detrimento do pouco tempo e de uma certa facilidade encontrada para a produção; a produção final foi o preenchimento das fichas; e, por fim, a distribuição foi o momento em que os alunos jogaram o jogo, seguido de sua doação para a biblioteca.

Na primeira aula, com duração de 50 minutos, procuramos saber, primeiramente, o conhecimento prévio dos alunos sobre a temática da mitologia grega. Foi uma aula expositiva e, para tanto, mostramos para eles, através de slides, um pouco da Grécia antiga, da mitologia, da relevância para nossa cultura, de alguns deuses e heróis específicos etc.

Tudo isso foi feito de forma breve, com o objetivo de expor um outro lado - aquele que foi base para a criação do universo da saga de Percy Jackson. Além disso, alguns dos personagens que mostramos tinham muita importância para a composição das fichas (que será explicado com detalhes mais à frente) e para o entendimento daquele e dos demais volumes da saga.

Esse foi nosso primeiro contato com a turma enquanto professoras e apesar de termos tido problemas com o data show, o que dispersou um pouco a atenção dos alunos num primeiro momento

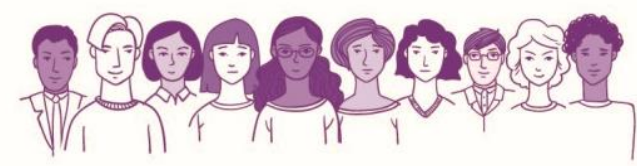


e reduziu o tempo da aula, conseguimos executar aquilo que foi proposto sem grandes dificuldades, tendo sido necessária apenas uma intervenção da professora regente para manter a ordem.

Durante a segunda, terceira, quarta e quinta aulas, começamos a desenvolver o trabalho com a leitura dos capítulos cinco e seis, adaptados em detrimento do tempo de aula, do volume 1 . Houve algumas interrupções porque aconteceu, no período de nossa intervenção, uma feira de leitura na escola, na qual os alunos participaram de algumas atividades. Embora fosse uma grande quantidade de texto, os alunos já estavam acostumados com esse tipo de trabalho, feito regularmente pela professora regente.

Durante a leitura dos textos, pedimos aos alunos que fizessem a leitura em voz alta para toda a turma por filas. A intenção era que, com a leitura desses capítulos, os alunos conseguissem compreender basicamente a história e conhecessem os principais personagens para fazerem a leitura do segundo livro da saga sem prejuízos ao entendimento.

Foram utilizadas as estratégias de leitura conforme Cafieiro (2005). Também fizemos interrupções para complementar informações sempre que necessário e pedimos a eles que fizessem uma legenda com lápis de cor (foi pedido previamente para que eles os levassem) marcando, nos textos que entregamos, as partes que descrevem oito personagens/lugares que são importantes para a montagem das fichas e que são retomados em Percy Jackson e o Mar de Monstros. A princípio, sentimos dificuldade de compreensão por parte dos alunos, mas, uma vez entendida a proposta, a atividade se deu tranquilamente.

Depois disso, ocupamos a sexta aula e parte da sétima para explicar o jogo em si e fazer as fichas. Nessas aulas, explicamos a nossa proposta de fazermos o nosso jogo: "Perfil Percy Jackson" (são as mesmas regras do jogo "Perfil", só que adaptado para o universo do volume um da saga). Para isso, esclarecemos, num primeiro momento, as características do jogo e o modo de jogar.

Logo após, detivemo-nos em fazer uma análise linguística das fichas junto com eles, como o uso da primeira pessoa, de adjetivos etc. Dessa forma, eles mesmos seriam capazes de perceber quais seriam as características necessárias para que o jogo tivesse sucesso - já que fazer as fichas de forma correta seria essencial para que tudo saísse como o esperado.

A partir daí, dividimos a turma em quatro grupos de oito alunos, entregamos a base das fichas (que foram feitas previamente por nós) e cada aluno confeccionou duas fichas, as quais eles preencheram com cinco dicas da caracterização do personagem ou local, previamente entregue a cada um deles. Como cinquenta minutos é pouco tempo para que tudo fosse explicado e que as dúvidas fossem tiradas, pedimos para que terminassem em casa.

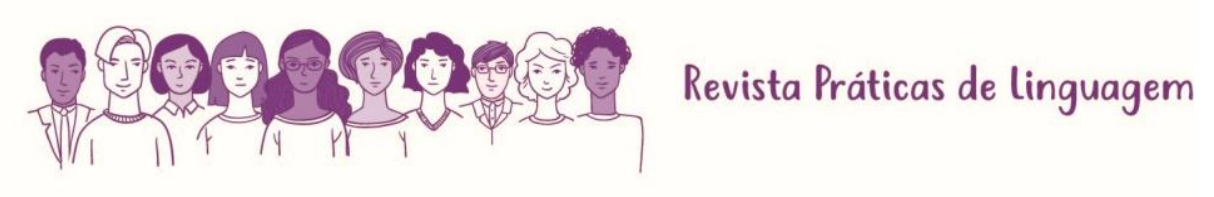


Nas aulas seguintes, que já eram as duas últimas (sétima e oitava aulas), ocupamos cerca de trinta minutos para fazer a correção das fichas através de uma lista de constatação que construímos junto com eles, retomando a aula de análise linguística. A lista de constatação, portanto, continha perguntas como: "minha ficha tem cinco dicas?", "alguma das dicas está muito óbvia?", "com as cinco dicas meus colegas serão capazes de adivinhar?", "em qual pessoa está meu texto?" etc.

Depois desse primeiro momento, trocamos as fichas feitas por eles entre os grupos e entregamos mais algumas fichas que foram feitas por nós com os personagens/lugares falados na primeira aula, para criar uma certa dificuldade. Além disso, distribuímos os tabuleiros feitos por nós para que eles passassem o restante da aula jogando na sala de leitura (usufruindo de um espaço novo na escola) onde eles ficaram muito mais organizados e confortáveis.

Durante o tempo em que eles jogaram (cerca de quarenta minutos), sentimos que eles ficaram muito envolvidos e que estavam muito empolgados. Nós passamos de mesa em mesa para observar se os alunos estavam tendo dificuldades e, como foi a primeira vez que o jogo foi desenvolvido e aplicado, percebemos que, de modo geral, eles tinham facilidade em acertar e, por isso, as rodadas acabavam muito rápido.

Isso não foi necessariamente um problema, porque eles acabaram jogando várias vezes, mas a professora sugeriu que passássemos nas mesas explicando novamente as regras. Com isso, percebemos que, para essa faixa etária, é preciso levar sempre tudo esquematizado, anotar e repetir várias vezes, porque eles têm tanta facilidade para aprender quanto têm para se dispersar daquilo que está sendo ensinado. Ademais, precisaremos fazer algumas modificações no jogo, como aumentar o número de casas.

Após os alunos jogarem, retornamos para a sala de aula e tivemos alguns minutos de conversa com eles para que tivéssemos um feedback sobre a nossa atuação enquanto professoras, sobre as atividades desenvolvidas e sobre o jogo que era o objetivo final.

Os alunos demonstraram ter gostado bastante do que foi proposto e executado por nós, apontando apenas algumas modificações no jogo em si. Já a professora, agradeceu e elogiou bastante o trabalho desenvolvido por nós, nos mostrando apenas algumas atitudes de cunho prático para manter a atenção dos alunos, o silêncio em sala (principalmente por se tratarem de alunos muito novos).

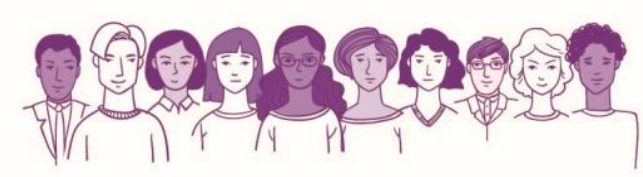




\section{Considerações finais}

O trabalho descrito, que fez parte da intervenção de Estágio Supervisionado em Língua Portuguesa, abriu espaço para reflexões não só acerca da importância desse momento na vida do futuro professor em formação inicial (se revelando, inclusive, como uma oportunidade para a criação de material didático autoral) mas principalmente como uma possibilidade diferenciada de trabalho com o Letramento Literário na Educação Básica.

A produção do jogo "Perfil", bem como todo o planejamento das aulas, que envolveu uma sequência didática, deixou claro que a escolha por esse gênero se mostrou interessante para o trabalho com caracterização de personagens, o que é um aspecto fundamental a ser aprendido pelo aluno do ensino fundamental, no que tange leitura literária, proporcionando a apropriação do gênero e contribuindo para um melhor entendimento do livro.

Por fim, esperamos que a publicação deste relato possa contribuir para a realidade de outros professores no trabalho voltado para os letramentos, sobretudo o literário, inseridos em práticas sociais contextualizadas, as quais não somente despertem o interesse dos alunos, mas também aumentem e tornem efetiva a participação deles em sala de aula.

\section{Referências}

ALBUQUeRQUe, E.; Telma F. Manual Didático: jogos de alfabetização. Pernambuco: MEC (2009). BAKHTIN, M. (1975) Questões de literatura e de estética: a teoria do romance. São Paulo, Hucitec/Unesp, 1993, 3a. edição.

BRASIL/MEC. Secretaria de Educação Fundamental. Parâmetros curriculares nacionais: primeiro e segundo ciclos do ensino fundamental: língua portuguesa/Secretaria de Educação Fundamental. Brasília: MEC/SEF, 1997.

BRANCO, A. A utilização do jogo "Perfil Botânico" como estratégia para o ensino de botânica. VIII ENCONTRO NACIONAL DE PESQUISA EM EDUCAÇÃO EM CIÊNCIAS, VIII (2011).

CAFIERO, D. "Leitura como processo." Caderno do Formador. Belo Horizonte: CEALE/FaE/UFMG, 2005.

CORREA, M. "Aspectos basilares do interacionismo sociodiscursivo: conceitos vygotskyanos revisitados." Linguagens \& Cidadania 14.1 (2016).

DOLZ, J.; NOVERRAZ, M.; SCHNEUWLY, B. Sequências didáticas para o oral e a escrita: apresentação de um procedimento. Gêneros orais e escritos na escola (2004): 95-128.

GOULART, R. S. "INTERAÇÃO, INTERACIONISMOS: SITUANDO O INTERACIONISMO

SOCIODISCURSIVO." Disponível em:

<http://jararaca.ufsm.br/websites/I\&c/download/Artigos10/raquel.pdf.pdf> Acesso em: 13/05/2017. MARCUSCHI, L. A. A QUESTÃO DO SUPORTE DOS GÊNEROS TEXTUAIS (parte 1). DLCV-Língua, Linguística \& Literatura 1.1 (2003).

de MIRANDA, Simão. "No Fascínio do jogo, a alegria de aprender." Linhas criticas (2002): 21.

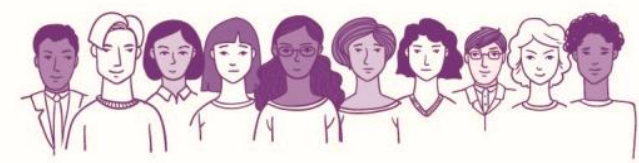


OLIVEIRA, A. D. S. GÊNEROS TEXTUAIS E PRÁTICAS SOCIAIS: A PRODUÇÃO DE UM JOGO DIDÁTICO. (2015). Disponível em:<http://www.ileel.ufu.br/anaisdosielp/wp-content/uploads/2014/11/889.pdf> Acesso em: 20/05/2017

RIORDAN, R. O ladrão de raios. Editora Intrinseca, 2011.

\section{Anexos}

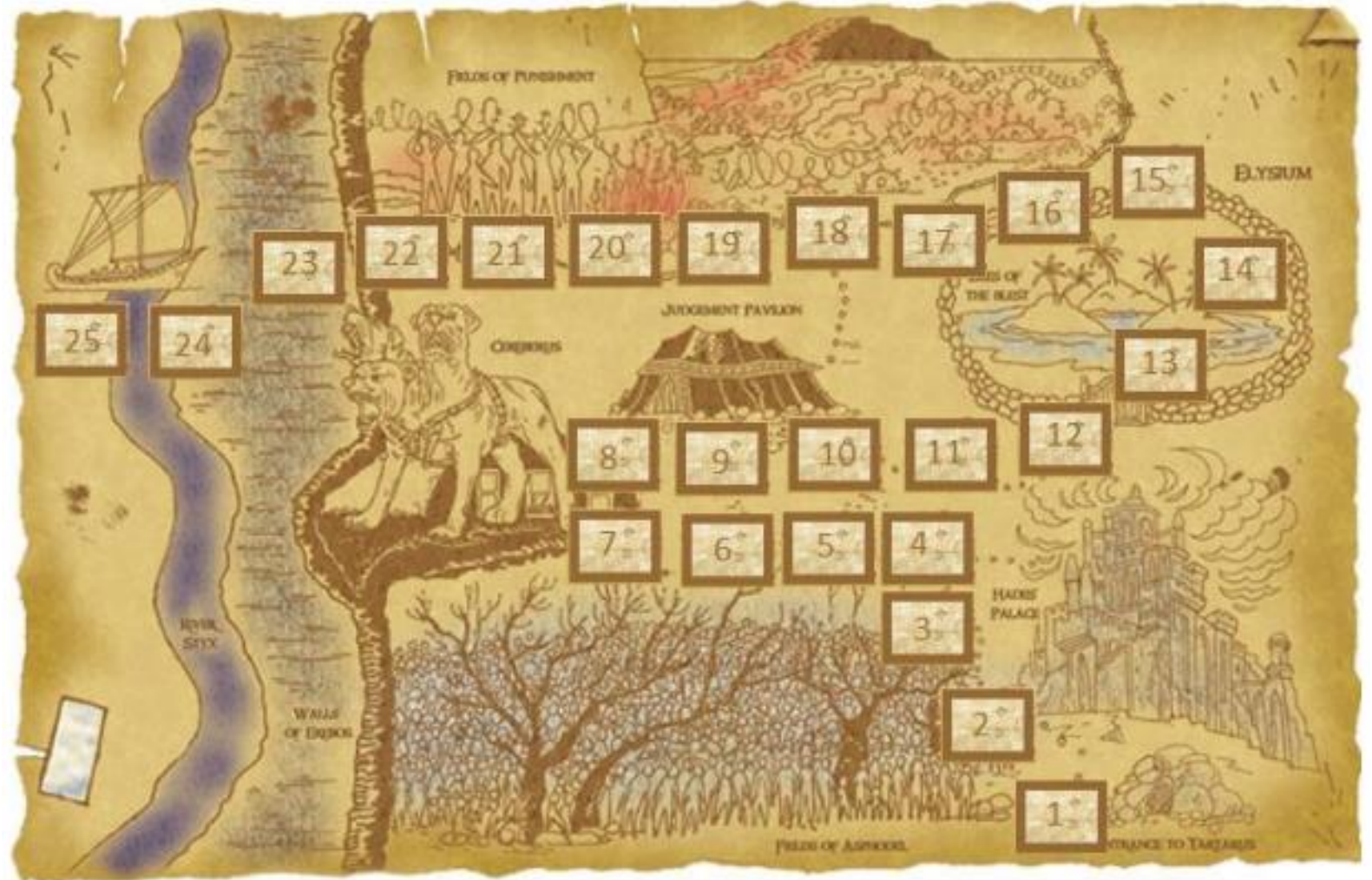

Figura 1: Tabuleiro do jogo Perfil Mitológico 


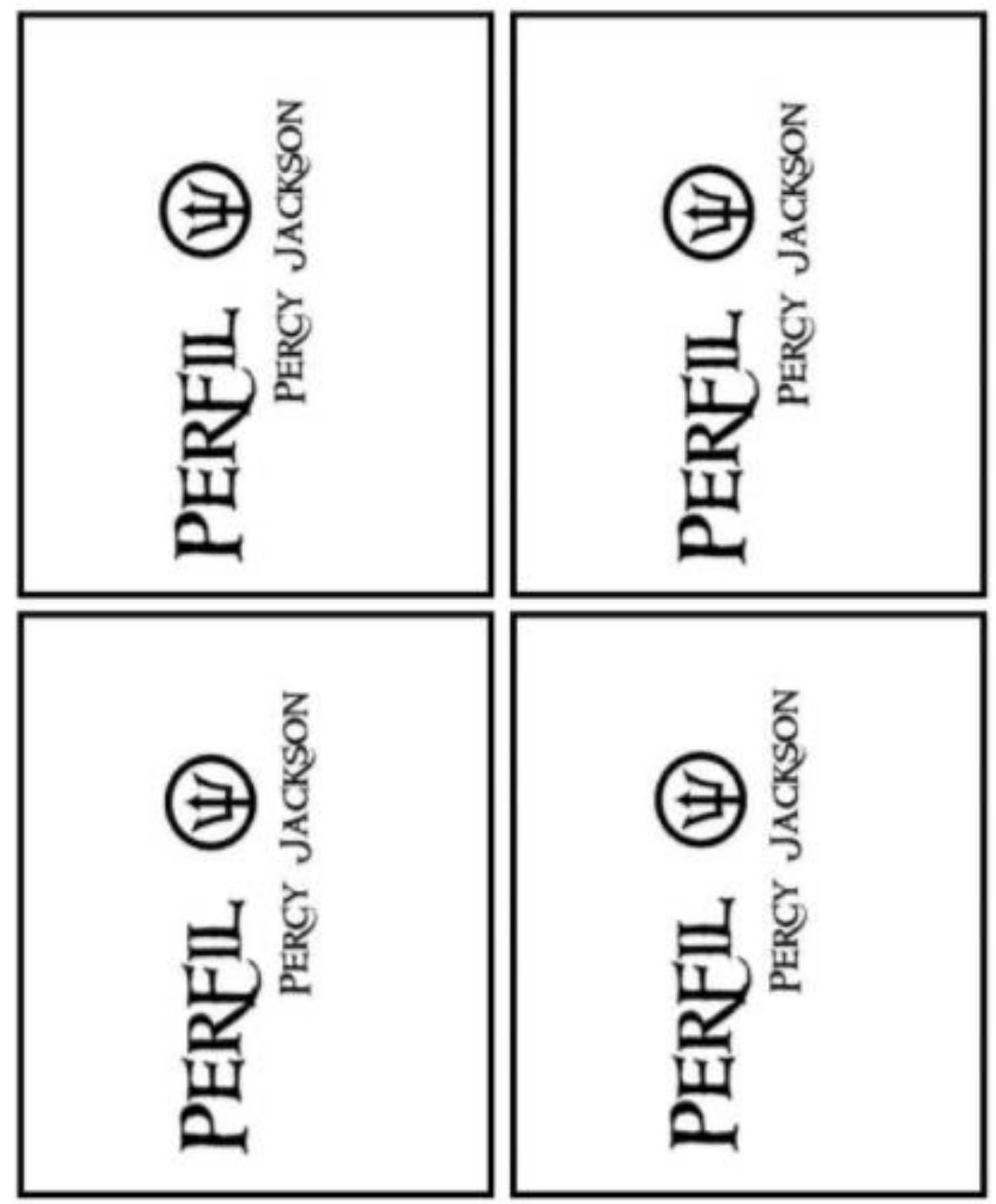

Figura 2: Verso das cartas para o jogo

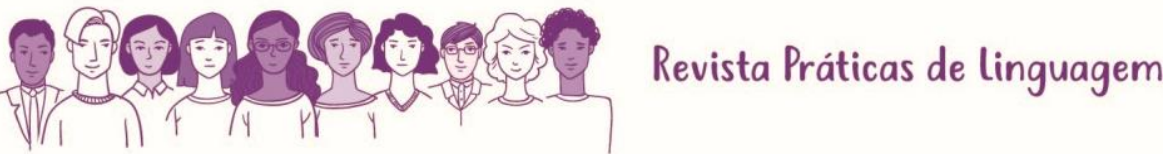




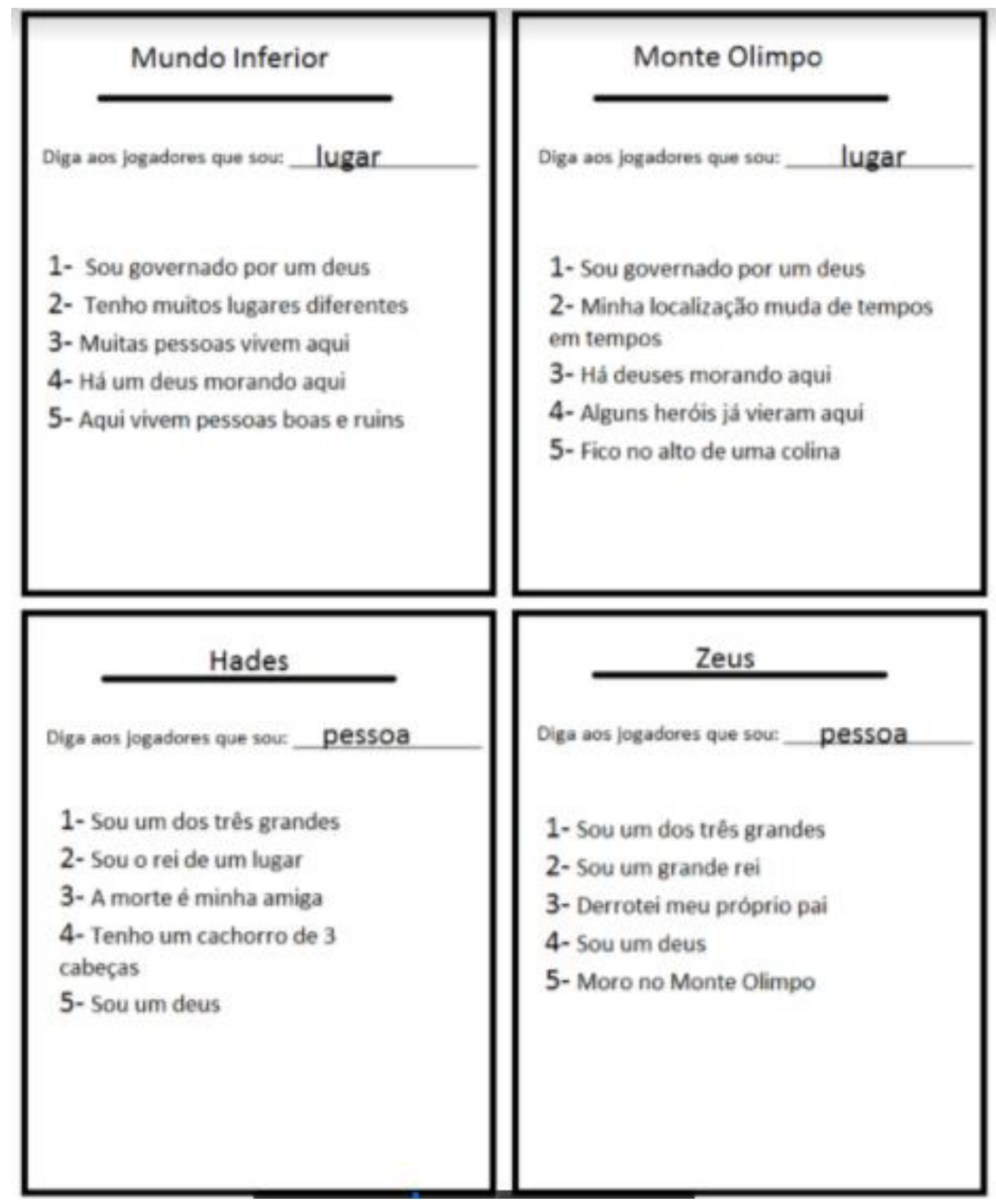

Figura 3: Exemplo de carta para produção 

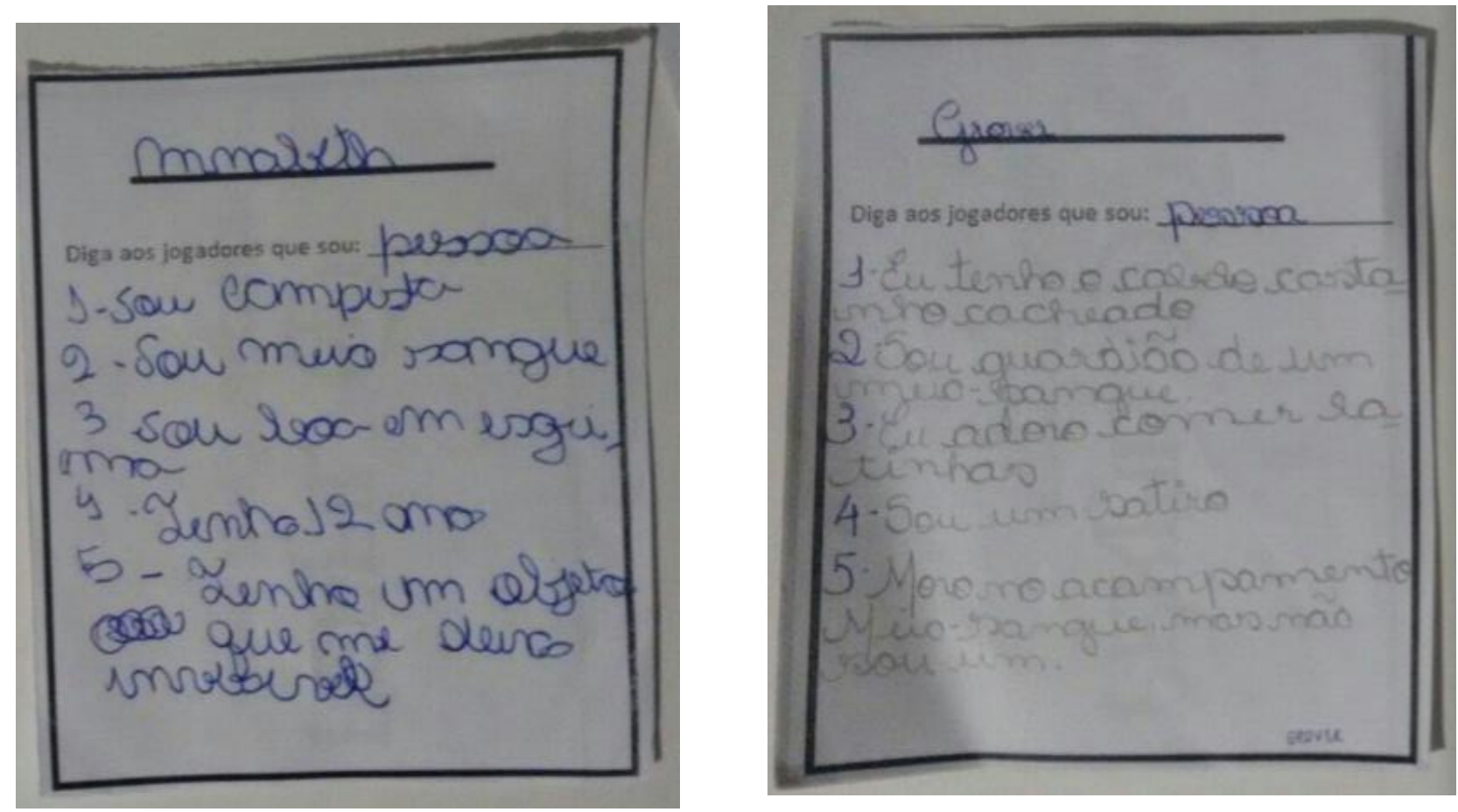

\section{Annabeth}

Diga aos jogadores que sou: pessoa

1- Sou campista

2- Sou meio sangue

3- Sou boa em esgrima

4- Tenho 12 anos

5- Tenho um objeto que me deixa invisível
Grover

Diga aos jogadores que sou: pessoa

1- Eu tenho o cabelo castanho e cacheado 2- Sou guardião de um meio-sangue

3- Eu adoro comer latinhas 4- Sou um sátiro

5- Moro no acampamento meio-sangue mas não sou um.

Figura 4: Exemplo de carta produzida pelos alunos.

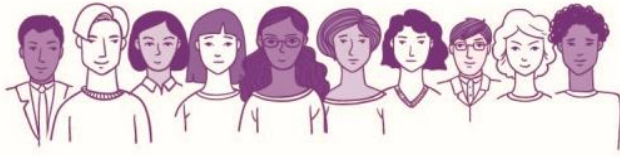

